\title{
Evaluation of the coagglutination test for the identification of Neisseria gonorrhoeae in primary cultures
}

\author{
N A JOHNSTON \\ From the VD Reference Laboratory, London Hospital Research Laboratories, London
}

SUMMARY The coagglutination (COA) test for the identification of Neisseria gonorrhoeae was compared with immunofluorescence and sugar degradation tests on 1710 gonococcal isolates, 72 of which produced $\beta$-lactamase. The COA test gave a positive result for $98.6 \%$ of the strains. Treatment of suspensions with Streptomyces enzyme reduced the incidence of inconclusive results due to autoagglutination to $1 \cdot 2 \%$. Cross-reactivity of the gonococcal antiserum was minimised by absorption with meningococci and Moraxella species. The COA provides a simple, quick, and reliable method for identifying $N$ gonorrhoeae in culture.

\section{Introduction}

The identification of Neisseria gonorrhoeae in primary cultures by conventional sugar degradation methods often requires subculture to obtain a pure growth of gonococci, so that results are not usually available for $24-48$ hours. Some strains of gonococci grow poorly on first isolation and ferment glucose feebly; difficulties may also arise from the use of impure reagents. Direct immunofluorescence tests with specific antigonococcal conjugates have been used to identify gonococci in primary culture, and although these give reliable results they require facilities for fluorescence microscopy.

A coagglutination test for identifying gonococci was described by Danielsson and Kronvall ${ }^{1}$; this gives a more rapid result and does not require specialised equipment. It is based on attachment of gonococcal antibody by its $\mathrm{Fc}$ portion to staphylococcal protein $\mathrm{A}$; subsequent reaction of the Fab determinants with gonococci produces clumping which can be detected visually by a slide test. Many workers have reported on the usefulness of this test. ${ }^{2-7}$

This study compares the results of the coagglutination (COA) test with those obtained by fluorescent antibody (FA) and sugar degradation tests on fresh

Address for reprints: Dr N A Johnston, VD Reference Laboratory, London Hospital Research Laboratories, Ashfield Street, London E1

Accepted for publication 2 April 1981 isolates of gonococci, other Neisseria species, and other organisms frequently isolated from the genital tract.

\section{Materials and methods}

BACTERIAL STRAINS

Bacterial strains tested were:

(1) 1160 strains of $N$ gonorrhoeae isolated from routine specimens from patients attending the Whitechapel Clinic, London Hospital, and 550 strains sent to the VD Reference Laboratory for identification and antibiotic sensitivity studies;

(2) 75 strains of Neisseria meningitidis of various groups;

(3) 72 isolates of other Neisseria species; and

(4) 70 strains of other bacterial species (Pseudomonas four, Haemophilus influenzae seven, Haemophilus parainfluenzae two, Streptococcus pyogenes group B 25, Staphylococcus epidermidis 20, and Escherichia coli 12).

\section{MEDIA}

Specimens were plated directly in the clinic on a selective medium containing brain heart infusion agar (Oxoid C17375), with 10\% defibrinated horse blood enriched with Gibco CVA supplement; vancomycin $(3 \mathrm{mg} / \mathrm{l})$ and colistin $(7.5 \mathrm{mg} / \mathrm{l})$ were added as inhibitory agents. Cultures were incubated for 24-48 hours at $35^{\circ} \mathrm{C}$ in an atmosphere of $8-10 \% \quad \mathrm{CO}_{2}$; Kellogg's serum-free medium ${ }^{8}$ was used in parallel 
with brain heart infusion medium to assess the effect of serum in the medium on the COA test. Oxidasepositive Gram-negative diplococci of typical colonial and microscopical morphology were selected for examination by COA, FA, and sugar degradation tests. Other Neisseria and bacterial species were identified by standard procedures. ${ }^{9}$ The serogroups of meningococcal isolates were determined. Strains were cultured on plates of hydrocoele agar for sugar degradation tests with (a) $1 \%$ glucose and (b) $1 \%$ maltose, lactose, and sucrose with phenol red as indicator ${ }^{10}$ Strains producing acid on plate (b) were further tested by inoculation of bijou bottles of Flynn and Waitkins medium ${ }^{11}$ containing the individual carbohydrates.

\section{ANTIGONOCOCCAL SERUM}

A polyvalent gonococcal antiserum was obtained from hyperimmunised rabbits by the methods described by Danielsson. ${ }^{6}$ Before use the antiserum was absorbed with formalinised strains of Neisseria meningitidis (groups $\mathrm{B}, \mathrm{Y}$, and $\mathrm{XYZ}$ ) and Moraxella species. ${ }^{6}$ The same antiserum was used to prepare an FITC conjugate for the FA tests and for sensitising staphylococci in the COA test.

\section{FLUORESCENT ANTIBODY TEST}

Gonococci were evenly suspended in $0.5 \%$ gelatin in phosphate-buffered saline $(\mathrm{pH} 7 \cdot 1)$ using a vortex mixer to give a barely perceptible turbidity, and a loopful was spread over an area $1 \mathrm{~cm}$ in diameter on a clean glass slide and allowed to dry. The slide was fixed in 50\% methanol in PBS for 10 minutes and washed in PBS; a drop of conjugate, diluted to its working titre in PBS, was added. The working dilution was based on the highest dilution of conjugate which gave bright staining of gonococci from cultures of a reference strain and no reactivity with other neisseriae. After incubation at $37^{\circ} \mathrm{C}$ for 30 minutes in a moist chamber the slides were washed with PBS for two five-minute periods, rinsed with distilled water, mounted in buffered glycerol $(\mathrm{pH}$ $\mathbf{8} \cdot 0$ ), and examined with a Reichert Zetopan microscope equipped for darkground illumination with an HBO 200 mercury vapour light source. A Balzer FITC interference filter, a 530-mm barrier filter, and $a \times 63$ immersion objective were used with $\times 10$ oculars.

Readings were classed as: ++ , bright peripheral fluorescence (positive); + , weaker peripheral fluorescence (doubtful); and \pm , very faint overall staining or no staining (negative).

Control strains of gonococci and meningococci were included in each batch of tests.

\section{COAGGLUTINATION TEST}

Reagents for the test were prepared by the method described by Danielsson and Kronvall. ${ }^{1}$ Staphylococcus aureus, strain Cowan 1 (NCTC 8530), was grown for 18 hours in Todd-Hewitt broth at $36^{\circ} \mathrm{C}$ in a shaking water-bath. The cells were then harvested by centrifugation; the pellet was washed three times in phosphate buffer $\mathrm{pH} 7 \cdot 2$, resuspended in $5 \mathrm{ml}$ of the same buffer containing $0.5 \%$ formalin for three hours, washed twice in PBS, resuspended, and heated at $80^{\circ} \mathrm{C}$ for five minutes. After additional washing the bacteria were suspended to $10 \% \mathrm{w} / \mathrm{v}$ in PBS containing $0 \cdot 1 \%$ sodium azide. The suspension of staphylococci was stored at $-20^{\circ} \mathrm{C}$ as this has been shown to enhance its stability. ${ }^{12}$ Before sensitisation the suspension was washed twice with PBS.

Sensitised test suspension. This was prepared by adding $0 \cdot 1 \mathrm{ml}$ of the absorbed antigonococcal serum to $1 \mathrm{ml}$ of the washed $10 \%$ suspension of staphylococci. This was thoroughly mixed and left for 10 minutes at room temperature, centrifuged at $2500 \times g$ for 15 minutes and the deposit washed twice in PBS. The sensitised cocci were finally suspended in $10 \mathrm{ml}$ of sterile PBS containing $0 \cdot 1 \%$ sodium azide.

Control suspension. This was similarly prepared with $0.1 \mathrm{ml}$ of normal rabbit serum in place of the antiserum. Both suspensions were stored at $4^{\circ} \mathrm{C}$ and remained usable for 2-3 months.

Test procedure. Two smears of growth were made on a glass slide with a platinum loop containing a few gonococcal colonies. The smears were left on the bench at room temperature for two minutes; one drop of sensitised gonococcal reagent was then thoroughly mixed with one smear by means of a platinum loop or wooden applicator and one drop of control suspension with the other. The slides were then rocked gently for 2-3 minutes and examined by eye for agglutination under oblique light against a dark background.

Alternatively, in those strains which showed autoagglutination by the direct smear method the growth from an 18-hour culture was suspended in PBS with a vortex mixer so that the suspension was free from visible particles. Twenty-five-microlitre volumes of the suspension were placed on two circled areas of a glass slide; $25 \mu \mathrm{l}$ of the test and control suspensions were added, thoroughly mixed, and rocked as described.

Tests were read as follows:

Positive: definite clumping of coarse or fine particles with sensitised reagent, the control remaining evenly turbid. Strong reactions appeared within 30 seconds; doubtful reactions were re-examined after constant rocking for 2-3 minutes. 
Negative: both suspensions evenly turbid with no visible clumping.

Autoagglutination: Irregular clumps and lacy strands with both suspensions.

\section{METHODS OF MINIMISING AUTOAGGLUTINA- TION}

The use of serum-free medium was proposed by Menck $^{3}$ to reduce the number of strains showing autoagglutination, but this was not effective in the present study. It has been suggested that heating such strains in a water-bath at $80-100^{\circ} \mathrm{C}$ for 20 minutes makes the results easier to read. ${ }^{7}$ Autoagglutinating strains were heated at $80^{\circ} \mathrm{C}$ for 5,15 , and 30 minutes, and centrifuged, and the antigen-containing supernatant retested. This enabled readings to be obtained with some strains but not with others.

The following enzymes were tested: trypsin 1\% (Difco), pronase $1 \%$ (purified), and Streptomyces enzyme. The latter was prepared as described by Maxted for group identification of streptococci ${ }^{13}{ }^{14}$ and was supplied by the Cross-Infection Reference Laboratory (PHLS, Colindale, Middlesex). It was used without further dilution and was found to be more efficient in reducing autoagglutination than the other enzymes tested. A $20-\mu$ l volume of the enzyme was added to each of the mixed staphylococcal and gonococcal suspensions on the slide, which was rocked slowly and observed for COA. An enzyme extract was prepared from those strains showing persistent autoagglutination after this treatment by taking a loopful of growth from an 18-hour culture on selective medium into $0.25 \mu \mathrm{l}$ of enzyme solution in a small tube. This was heated in a water-bath at $50^{\circ} \mathrm{C}$ for about 30 minutes and the clear supernatant used in the test.

\section{Results}

In the first part of the study 728 strains of $N$ gonorrhoeae were tested by the three methods described (table I). The COA test gave definite positive results with $664(91 \cdot 2 \%)$ strains, but readings could not be made with 64 isolates which gave inconclusive results because of autoagglutination.

The effect of Streptomyces enzyme, as used in the Lancefield grouping of streptococci by slide agglutination, was investigated during tests on a further 982 gonococcal isolates. Tests performed with this enzyme were generally easier to read, and in particular the results obtained on many autoagglutinating strains were more confidently interpreted. In this series definite positive reactions were obtained with $968(98 \cdot 6 \%)$ strains; only $1 \cdot 2 \%$ inconclusive results were recorded compared with $8.8 \%$ in the first series (table I). The Streptomyces enzyme was also found to be effective in tests using commercially available COA reagents (Phadebact Gonococcus Test, Pharmacia Diagnostics, Uppsala, Sweden).

The FA test gave positive results for $1607(94 \cdot 0 \%)$ and doubtful results for $92(5 \cdot 4 \%)$ of the 1710 strains in the combined series. The sugar degradation tests gave unequivocally positive results for $1695(99 \cdot 1 \%)$; $15(0.9 \%)$ strains failed to ferment glucose (these were usually slow-growing atypical isolates, seven of which were obtained from disseminated gonococcal infections and five from extragenital sites). The COA gave positive results with these strains but the FA test result was doubtful in nine.

Two strains which had been isolated in Australia and gave sugar degradation reactions specific for $N$ gonorrhoeae but doubtful results in the gonococcal FA test gave negative results by the COA.

Of the 1710 strains of $N$ gonorrhoeae, 72 produced $\beta$-lactamase. The COA gave a positive result for all these strains. The FA result, however, was definitely positive in only 40 , and 29 strains showed doubtful fluorescence and three gave negative results.

Two strains of meningococci of serogroups $\mathrm{XYZ}$ and $\mathrm{W} 135$ gave positive COA test results. The other Neisseria species (table II) tested were either COAnegative or gave inconclusive results because the

TABLE I Comparison of results of coagglutination (COA), fluorescent antibody (FA), and sugar degradation tests on 1710 strains of Neisseria gonorrhoeae

\begin{tabular}{|c|c|c|c|c|c|c|c|c|c|}
\hline \multirow[b]{3}{*}{$\begin{array}{l}\text { Treatment of } \\
\text { suspension }\end{array}$} & \multirow[b]{3}{*}{$\begin{array}{l}\text { No of } \\
\text { strains }\end{array}$} & \multicolumn{8}{|c|}{ Results of tests (\%): } \\
\hline & & \multicolumn{3}{|l|}{$C O A$} & \multicolumn{3}{|l|}{$F A$} & \multicolumn{2}{|c|}{ Carbohydrate reactions } \\
\hline & & ++ & - & 0 & ++ & + & - & Positive* & Negative $†$ \\
\hline \multirow{2}{*}{$\begin{array}{l}\text { None } \\
\text { Streptomyces } \\
\quad \text { enzyme }\end{array}$} & 728 & $664(91 \cdot 2)$ & 0 & $64(8 \cdot 8)$ & $688(94 \cdot 5)$ & $38(5 \cdot 2)$ & $2(0 \cdot 1)$ & $722(99 \cdot 2)$ & $6(0 \cdot 8)$ \\
\hline & 982 & $968(98 \cdot 6)$ & 2 & $12(1 \cdot 2)$ & $919(93 \cdot 6)$ & $54(5 \cdot 5)$ & $9(0 \cdot 9)$ & $973(99 \cdot 1)$ & $9(0 \cdot 9)$ \\
\hline Total & 1710 & 1632 & 2 & 76 & 1607 & 92 & 11 & 1695 & 15 \\
\hline
\end{tabular}

*Glucose + , maltose - , lactose - , sucrose -

+Glucose - , maltose -', lactose -', sucrose-

$++=$ positive,$+=$ doubtful, $-\stackrel{\text { = negative, } 0=\text { inconclusive }}{=}$ 
TABLE II Results of coagglutination and fluorescent antibody tests on Neisseria and related species (with absorbed reagents)

\begin{tabular}{|c|c|c|c|c|c|c|c|}
\hline \multirow[b]{2}{*}{ Species } & \multirow[b]{2}{*}{ Strains } & \multicolumn{3}{|c|}{ Coagglutination test } & \multicolumn{3}{|c|}{ Fluorescent antibody test } \\
\hline & & ++ & - & 0 & ++ & + & - \\
\hline $\begin{array}{l}N \text { meningitidis } \\
N \text { mucosa } \\
N \text { subflava } \\
N \text { flavescens } \\
N \text { lactamica } \\
N \text { sicca } \\
N \text { pharyngis } \\
B r \text { catarrhalis } \\
\text { Moraxella species }\end{array}$ & $\begin{array}{r}75 \\
3 \\
4 \\
3 \\
3 \\
12 \\
9 \\
14 \\
15 \\
12\end{array}$ & 2 & $\begin{array}{r}71 \\
3 \\
4 \\
3 \\
9 \\
3 \\
14 \\
14 \\
14 \\
9\end{array}$ & $\begin{array}{l}3 \\
6 \\
1 \\
3\end{array}$ & $\begin{array}{l}2 \\
0\end{array}$ & 3 & $\begin{array}{r}72 \\
3 \\
4 \\
3 \\
3 \\
10 \\
9 \\
14 \\
15 \\
12\end{array}$ \\
\hline Total & 147 & 2 & 130 & 15 & 2 & 3 & 142 \\
\hline
\end{tabular}

++ positive, $+=$ doubtful, $-=$ negative, $0=$ inconclusive

strains were autoagglutinable. No positive COA test results were obtained with the 70 strains of other organisms listed above.

\section{Discussion}

The identification of $N$ gonorrhoeae in primary culture by conventional sugar degradation tests has been reviewed by Shtibel and Toma ${ }^{15}$ and Young et $a l .{ }^{16}$ These methods usually incur a delay of at least 24 hours before final identification. Serological techniques for identification reduce this delay and results are usually available on the day the primary culture is examined. The FA technique requires specialised equipment and experience in fluorescence microscopy but gives good results if a specific conjugate is used. In particular, this conjugate should have adequate reactivity with local strains of gonococci and should be absorbed to remove crossreacting antibodies to other species of Neisseria and related bacteria.

The COA test, however, requires no specialised equipment and the result is available within a few minutes. The present study has confirmed earlier reports in which the COA, FA, and sugar degradation tests were compared and has shown that the COA test provides an accurate means of identifying most strains of gonococci. Nevertheless sugar utilisation or FA tests should also be used for identifying problem strains isolated from extragenital sites.

The finding of two Australian strains identified as $N$ gonorrhoeae on the basis of sugar degradation reactions which gave negative results in the COA test may reflect geographical differences in antigenic profile. ${ }^{17}$ This underlines the necessity for raising an antigonococcal serum known to be reactive in the COA test with local gonococcal strains.

Inconclusive results due to autoagglutination of some strains may be minimised by using the Strep- tomyces enzyme and this appears to be more effective and less time-consuming than methods using heat or subculture on serum-free media. Although reagents for the COA test are available commercially, they are not difficult to prepare in the laboratory. Reactivity with other neisseriae is avoided by absorption of the gonococcal antiserum.

The coagglutination test provides a simple specific method suitable for identifying $N$ gonorrhoeae in general microbiological laboratories.

I wish to thank $\mathrm{Dr} G$ Johnston and $\mathrm{Dr} A \mathrm{E}$ Wilkinson for helpful advice and critical review of the manuscript. I am indebted to Dr W R Maxted (PHLS, Colindale, Middlesex) for the supply of Streptomyces enzyme; to Dr J D Abbot (PHLS, Manchester), who provided the meningococcal reference strains; and to $\mathrm{Dr} J$ Speight (Pharmacia Diagnostics, Uppsala, Sweden) for providing Phadebact reagents. This work was supported by a grant from the World Health Organisation.

\section{References}

1. Danielsson D, Kronvall G. Slide agglutination method for the serological identification of $N$ gonorrhoeae with antigonococcal antibodies absorbed to protein-A-containing staphylococci. Appl Microbiol 1974; 27:368-74.

2. Olcén P, Danielsson D, Kjellander J. The use of protein-Acontaining staphylococci sensitised with anti-meningococcal antibodies for grouping $N$ meningitidis and demonstration of meningococcal antigen in cerebrospinal fluid. Acta Patho Microbiol Scand (B) 1975; 83:387-96.

3. Menck $H$. Identification of $N$ gonorrhoeae in cultures from tonsillopharyngeal specimens by means of a slide coagglutination test (Phadebact Gonococcus Test). Acta Pathol Microbio Scand (B) 1976;84: 139-44.

4. Barnham M, Glynn AA. Identification of clinical isolates of $N$ gonorrhoeae by a coagglutination test. J Clin Pathol 1978;31: $189-93$.

5. Olcén P, Danielsson D, Kjellander J. Laboratory identification of pathogenic neisseriae with special regard to atypical strains. An evaluation of sugar degradation, immunofluorescence and coagglutination tests. Acta Pathol Microbiol Scand (B) 1978; 86:327-34. 
6. Danielsson D, Sandström E. Serology of $N$ gonorrhoeae. Demonstration of strain-specific antigens by immunoelectrophoresis, immunofluorescence, and coagglutination techniques. Acta Pathol Microbiol Scand (B) 1979;87:55-64.

7. Lewis JS, Martin JE. Evaluation of the Phadebact gonococcus test: a coagglutination procedure for confirmation of $\mathbf{N}$ gonorrhoeae. J Clin Microbiol 1980;11:153-6.

8. Kellogg DS et al. Virulence genetically linked to colonial variation. J Bacteriol 1963; 85: 1274-9.

9. Cowan ST. Cowan and Steel's Manual for Identification of Medical Bacteria. 2nd ed. Cambridge: Cambridge University Press, 1974

10. Public Health Laboratory Service. Laboratory diagnosis of venereal disease PHLS Monograph Series 1. 1972;1:37.

11. Flynn J, Waitkins SA. A serum-free medium for testing fermentation reactions in $N$ gonorrhoeae. J Clin Pathol 1972; 25: 525 .
12. Goding JW. Use of staphylococci protein-A as an immunological reagent. J Immunol Methods 1978; 20:241-53.

13. Maxted WR. Preparation of streptococcal extracts for Lancefield grouping. Lancet 1948; ii: 255-6.

14. Maxted WR, Efstratiou A, Parker MT. Agglutination grouping of streptococci (letter). Lancet 1976; ii:692-3.

15. Shtibel R, Toma S. $N$ gonorrhoeae: evaluation of some methods used for carbohydrate utilisation. Can J Microbiol 1978; 24: 177-81.

16. Young $\mathbf{H}$, Paterson IC, MacDonald DR. An appraisal of a rapid carbohydrate utilisation test for the identification of $N$ gonorrhoeae. WHO/VDT/RES/GON/75.91, 1975.

17. Catlin BW. Nutritional requirements and auxotyping. In: Roberts RB, ed. The Gonococcus. New York: John Wiley \& Sons, 1977;91-109. 